\title{
Navorsingsbriewe
}

\section{Verdedigingsekresies van die graanstinkluis Macchiademus diplopterus (Heteroptera: Lygaeidae)}

Ontvang 24 Mei 1996; aanvaar 8 Augustus 1996

\begin{abstract}
Defensive secretions of the grain stink bug Macchiademus diplopterus (Heteroptera: Lygaeidae)

Macchiademus diplopterus is a pest of wheat in South Africa. Large numbers of insects were collected from underneath exfoliating bark of Eucalyptus spp. growing near wheat fields in the Western Cape Province during January to March 1995. Volatile substances were collected with charcoal or Ambersorb as trapping agent. The adsorbent and the appropriate controls were eluted sequentially with dichloromethane and benzene. The resulting solutions were analized by gas chromatography and gas chromatography- mass spectrometry and identifications were made by comparing mass spectra and GC retention times to those of standards. The objective was to collect and identify these materials to establish backgrounds above which additional semiochemicals might be detected. In all cases, the mixtures of trapped volatiles consisted largely of only a few components, the most abundant of which were tridecane (ca.54\%), (E) -2-octenal (ca. 21\%) and (E)-2-hexenal (ca. 15\%). (E)-2-octen-1-ol acetate, (E)-2-hexen-1-ol acetate and (E)-4-oxo-2-octonal made up most of the remaining mixture (hexenal and an isomer of (E)-2-octenal were also observed.) No differences were noted between volatile substances of the different sexes. We conclude that these substances are the principal constituents of this insect's defensive secretions. Investigations into the sex pheromones will have to be conducted at a time when insects are sexually active.
\end{abstract}

\section{INLEIDING}

Die graanstinkluis Macchiademus diplopterus (voorheen beskryf as Blissus diplopterus) is 'n plaagorganisme wat van tyd tot tyd probleemafmetings aanneem en sedert 1992 weer in dele van die Suid- en Wes-Kaap voorkom en ekonomies betekenisvolle skade kan veroorsaak. 'Hierdie stinkluis kan ook 'n moeilik beheerbare plaag wees by uitvoervrugte, waaronder appelkose en perskes, omdat dit neig om weg te kruip in diep dele van die vrug waar opsporing problematies is. $^{2}$

Die volksnaam, stinkluis, verwys na die teenwoordigheid van verdedigingsekresies. Die reuk van 'n beskadigde of geirriteerde organisme herinner aan dié van groter en volledig bestudeerde stinkbesies (Pentatomidae) uit ander wêrelddele. ${ }^{3}$ $\mathrm{Na}$ die beste van ons wete is die chemiese ekologie van Macchiademus diplopterus of dié van verwante Blissusspesies, wat belangrike plae in ander wêrelddele is, nog nie ondersoek nie. In die Wes-Kaap oorsomer (estiveer) die luise in die volwasse stadium. Hulle beweeg normaalweg in Junie of Julie na die graanlande en lê eiers op jong plante. In hierdie periode vind feromoonsekresie gewoonlik plaas. Afhangende van temperatuurtoestande broei die eiers binne ' $n$ maand uit waarna ses nimfstadiums gedurende die volgende ses weke volg voordat die volwasse stadium bereik word. Verskeie opeenvolgende generasies kan dus in een seisoen 'n graanland aanval. Later beweeg die volwassenes onder warmer toestande uit die graanlande na die bas van vrugtebome, bloekombome en wingerde waar hulle oorsomer.

Die geleentheid het hom van Januarie tot Maart 1995 voorgedoen om groot getalle van die organismes te versamel sodat die vlugtige verbindings wat deur die stinkluis geproduseer word, ondersoek kon word. Die oogmerk van die ondersoek was om die vlugtige verbindings in die uitskeidings te identifiseer.

Die vrystelling van verdedigingschemikalieë deur
Macchiademus diplopterus vind normaalweg plaas sodra die insekte versteur word en was onvermybaar. 'n Tipiese onwelriekende geur was telkens waarneembaar sodra die organisme gehanteer is. Die oogmerk was dus om die verbindings te versamel en te identifiseer as kontrolewaardes ten einde bykomende semiochemikalieë te kan bepaal. Die gebruik van geslagsferomone deur Heteroptera is bekend ${ }^{3}$ en aggregasie- of versamelingsferomone verteenwoordig 'n derde moontlike kategorie kommunikasiechemikalieë naas verdedigingschemikalieë.

In hierdie ondersoek het die tydstip van versameling van die insekte en van die vlugtige verbindings egter saamgeval met die periode van estivering van die organismes, sodat die produksie van feromone nie verwag kon word nie.

\section{MATERIAAL EN METODES}

Groot getalle insekte is tussen Januarie en Maart 1995 in die Wes-Kaap, hoofsaaklik onder die los bas van verskillende bloekombome (Eucalyptus spp.) naby graanlande versamel. Onbeperkte getalle was beskikbaar en bloekombome langs landerye in Citrusdal het binne enkele minute duisende insekte opgelewer. Die skeiding van die geslagte was tydrowend aangesien individuele hantering en mikroskopiese ondersoek nodig was. Vlugtige stowwe is opgevang deur gebruik te maak van 'n apparaat soos beskryf deur Aldrich, Kochansky \& Abrams, ${ }^{4}$ met houtskool of Ambersorb as opvangagens. Vlugtige verbindings is opgevang deur lug met behulp van 'n vakuumlyn in te suig deur 'n geaktiveerde houtskoolfilter en deur 'n Pyrex-silinder ( $250 \mathrm{~mm}$ x $50 \mathrm{~mm}$ ) waarin die insekte gehuisves is en vervolgens deur ' $n$ klein opvanger wat of geaktiveerde houtskool of Ambersorb bevat het. Beide hierdie absorbeerdes is vooraf skoongemaak en is termies stabiel sodat dit kort voor gebruik tot $400{ }^{\circ} \mathrm{C}$ verhit kon word. Alle glaskomponente is soortgelyk vir verskeie ure verhit om alle vlugtige organiese verbindings te verwyder 
Die belugtingseksperiment is op gemengde groepe van albei geslagte uitgevoer kort na versameling en is daarna met verskillende geslagte herhaal. Die versameling van vlugtige verbindings is in twee stadiums gedoen. Eerstens is die insekte versigtig in die Pyrex-silinder geplaas om die vrystelling van verdedigingsekstresies te minimaliseer. Die silinder is in gedempte lig gehou. Die beligting is oomag uitgevoer. waarna die opvanger vervang is en die apparaat helder verlig is met ' $n$ sonlamp vir intervalle van 15 minute om oormatige temperatuurstyging te voorkom. Die lig en gepaardgaande verwarming het die insekte opmerklik geirriteer en die verwagting was dat dit tot vrystelling van verdedigingsekresies sal lei. Dieselfde prosedure is met geakklimatiseerde insekte herhaal.

Die opvangagens is opeenvolgens geèlueer met dichlorometaan en bensien. Die eerste adsorbeerder was voldoende aangesien baie min bykomende materiaal deur die tweede herwin is. Die resulterende oplossings is met behulp van gaschromatografie en gaschromatografie-massaspektrometrie ontleed. Identifikasies is gedoen deur massaspektra en GC-retensietye met dié van standaarde te vergelyk.

Omdat die volwasse insekte in 'n oorsomingstoestand was, kon die sekresie van feromone nie verwag word nie. Daar is probeer om die probleem te oorkom deur die insekte in 'n klimaatkamer te huisves waar sowel daglengte as temperatuur geprogrammeer kon word om die toestande in Mei en Junie te simuleer wanneer die jong graanplante ontkiem en uitgroei. Graan is in dieselfde klimaatkamer in houers ontkiem ingeval vlugtige plantsekresies ' $n$ bykomende paringsein sou verskaf. Geplukte groen blare van die graan is ook daagliks in die klimaatkamer geplaas. Die klimaatkamer is geprogrammeer volgens 'n skedule van lig:donker van 11:13 ure met 'n nagtemperatuur van $12{ }^{\circ} \mathrm{C}$ wat geleidelik gestyg het tot $20^{\circ} \mathrm{C}$ gedurende ligure. Gaschromotografie is met behulp van 'n Shimadzu GC9A uitgevoer wat met 'n vlam-ionisasiedetektor en 'n 30 meter DB-1 kolom toegerus is en geprogrammeer is vanaf 50 tot $250^{\circ} \mathrm{C}$ of $275^{\circ} \mathrm{C}$. Geraamde persentasies van komponente is verkry deur integrasie van pieke met behulp van 'n Shimadzu (R501) Chromatopac en is nie gekorrigeer vir detektorresponse of ander veranderlikes nie. Massaspektra is met behulp van 'n Hewlett Packard 5971 MSI massaspektrometer verkry of met behulp van ' $n$ Finnegan Incos 50 massaspektrometer. Identifikasies is gedoen deur vergelyking van sowel gaschromatografiese retensietye as massaspektra met sintetiese standaarde of komponente van vooraf geïdentifiseerde mengsels.

\section{RESULTATE EN BESPREKING}

In alle gevalle het die mengsels uit geadsorbeerde vlugtige verbindings bestaan waarvan die volopste tridekaan (ca. 54\%), (E)-2-oktenaal asetaat (ca. $21 \%$ ) en (E)-2-heksenaal (ca.15\%) was. (E)-2-okten-1-ool asetaat en (E)-hekseen-1ool asetaat en (E)-4-okso-2-oktenaal het die meeste van die oorblywende mengsel uitgemaak (figuur 1). Heksenaal en 'n isomeer van (E)-2-oktenaal is ook waargeneem, maar elkeen het minder as een persent van die totale vlugtige verbindings verteenwoordig. Geen betekenisvolle verskille in vlugtige verbindings is tussen die twee geslagte onderskei nie en ook nie tussen insekte wat versamel is voor en na die poging tot akklimatisering nie. Al hierdie verbindings is reeds voorheen geïdentifiseer as sekresies van die dorsale abdominaal-en/of metatorakskliere; die gevolgtrekking is dat hulle die hoofbestanddele vorm van die graanluis se verdedigingsekresies. Ondersoeke na die geslagsferomone van Macchiademus diplopterus sal uitgevoer moet word op 'n tydstip wanneer hulle geslagtelik aktief is.

Feromoonbeheerde aggregasiegedrag is waarskynlik ook by die insekte aanwesig. Groot groepe is tydens versamelings teëgekom. Na raming kan meer as 'n honderdduisend insekte onder die bas van 'n enkele bloekomboom oorsomer.

In aanhouding in die laboratorium, toe geriffelde karton in die hokke geplaas is, was verspreiding in die tonnels nie ewekansig nie. Sommige tonnels was diggepak met insekte terwyl ander leeg gebly het. Die stimuli wat betrokke is om hierdie gedrag te bewerkstellig, is onseker en geen getuienis bestaan dat die semiochemikalieè wat in hierdie ondersoek geïdentifiseer is 'n rol speel in die aggregasiegedrag van die stinkluis nie.

Oortollige insekte is oomag in heksaan gelaat en die vloeistof is daarna gefiltreer en gekonsentreer.

'n Groot hoeveelheid bleekgeel was is herwin $(1,75 \mathrm{~g}$ vanaf $38 \mathrm{~g}$ van Macchiademus diplopterus).

Gaschromatografiese analise het getoon dat tridekaan die volopste vlugtige deel van die was uitgemaak het, met oktonaal en oktenielasetaat ook teenwoordig. Die meer vlugtige verbindings kon tydens konsentrasie verlore geraak het. ' $n$ Paar verbindings wat later geèlueer het en wat nie in belugtingsmonsters teěgekom is nie, was ook sigbaar. 'n Vergelyking voor en na behandeling met diasometaan het klein hoeveelhede van verskillende vetsure opgelewer. Hulle was stearien-, oleln-palmitien- en palmitoeinsuur wat tentatief geïdentifiseer is deur die retensietye van hulle metielesters met dié van standaarde te vergelyk. Almal het in klein hoeveelhede voorgekom met nie een wat meer as $2 \%$ van die totale vlugtige stowwe verteenwoordig het nie. 'n Vergelyking van die somtotaal van detektorresponse met dié van 'n standaardoplossing tridekaan het aangedui dat minder as $20 \%$ van die ingespuite monster van die gaschromatografiekolom benede $275^{\circ} \mathrm{C}$ geèlueer kon word. Gevolglik, hoewel die was geredelik oplosbaar in heksaan is, het dit grotendeels uit relatief nievlugtige stowwe bestaan. Geen verskille tussen die geslagte kon ook in hierdie geval gevind word nie.

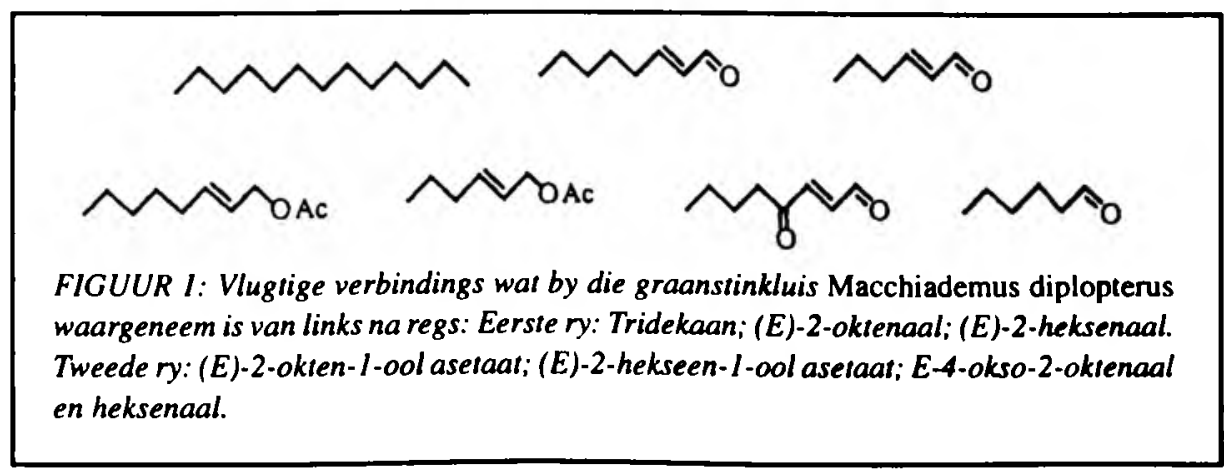




\section{J.E. OLIVER}

Insect Chemical Ecology Laboratory, Agriculture Research Service, U.S.D.A. Barc-W., Beltsville, Maryland 20705 2350, U.S.A.

\section{A.J. REINECKE* \& S.A. REINECKE}

Departement Soölogie, Universiteit van Stellenbosch, Stellenbosch, 7600

\section{BEDANKINGS}

Die outeurs bedank me. Mari de Beer en Laura Vermeulen, en mnr. Charles Bayman vir laboratoriumassistensie; mnr. Jan van As vir hulp met apparaat, mnr. Dave de Vilbiss en me. Sini Panicker vir massaspektra en drr. Kobus Laubser, Fanie Walters en Jeffrey Aldrich vir inligting en konsultasie. Verwysing $n a$ ' $n$ handelsproduk impliseer nie endosering deur die V.S.A. se Departement van Landbou nie. Finansiële steun deur die Stigting vir Navorsingsontwikkeling word met dank erken.

\section{LITERATUURVERWYSINGS}

1. Claasen, J. \& Laubscher, K. (1994). Graanstinkluis: moet ek spuit of nie? Landbouweekblad, 8 April, 36-37.

2. Myburgh, A.C. \& Kriegler, P.J. (1967). The grian stinkbug, Blissus diploterus Dist. as a pest of export fruit, with special reference to its cold-hardiness, J. Ent. Soc. S. Africa, 29, 90-95.

3. Aldrich, J.R. (1988). Chemical ecology of the Heteroptera, Ann. Rev. Entomol. 13, 211-238.

4. Aldrich, J.R. Kochanskry, J.P. \& Abrams, C.B. (1984). Attractant for a beneficial insect and its parasitoid: Aggregation pheromone of the predatory spined soldier bug Pedisus maculiventris (Hemiptera: Pentatomidae), Environ Entomal., 13, 1031-1036.

5. Blum, M.S. (1981). Chemical defenses of Arthropods (Academic Press. New York.)

- Outeur aan wie korrespondensie gerig kan word. 